\title{
Involvement of TRP Channels in Adipocyte Thermogenesis: An Update
}

\author{
Wuping Sun ${ }^{1 \dagger}$, Yixuan $\mathrm{Luo}^{2 \dagger}$, Fei Zhang ${ }^{2}$, Shuo Tang ${ }^{3 *}$ and Tao Zhu ${ }^{4 *}$ \\ 'Department of Pain Medicine and Shenzhen Municipal Key Laboratory for Pain Medicine, Shenzhen Nanshan People's \\ Hospital and The 6th Affiliated Hospital of Shenzhen University Health Science Center, Shenzhen, China, ${ }^{2}$ Department \\ of Cardiovascular Surgery, Shenzhen Nanshan People's Hospital and The 6th Affiliated Hospital of Shenzhen University \\ Health Science Center, Shenzhen, China, ${ }^{3}$ Department of Orthopaedics, The Eighth Affiliated Hospital, Sun Yat-sen \\ University, Shenzhen, China, ${ }^{4}$ Department of Respiratory Medicine, Second Affiliated Hospital of Chongqing Medical \\ University, Chongqing, China
}

OPEN ACCESS

Edited by:

Maria Elena De Lima, Grupo Santa Casa BH, Brazil

Reviewed by:

Karla S. Fernandes,

Instituto de Ensino e Pesquisa Santa

Casa BH, Brazi

Célio José Castro Junior

Grupo Santa Casa BH, Brazil

${ }^{*}$ Correspondence:

Tao Zhu

zhutao063020@163.com

Shuo Tang

tangshuo1205@163.com

${ }^{\dagger}$ These authors have contributed

equally to this work

Specialty section:

This article was submitted to

Cellular Biochemistry,

a section of the journal

Frontiers in Cell and Developmental

Biology

Received: 26 March 2021

Accepted: 02 June 2021

Published: 24 June 2021

Citation:

Sun W, Luo Y, Zhang F, Tang S and Zhu T (2021) Involvement of TRP

Channels in Adipocyte

Thermogenesis: An Update. Front. Cell Dev. Biol. 9:686173. doi: 10.3389/fcell.2021.686173
Obesity prevalence became a severe global health problem and it is caused by an imbalance between energy intake and expenditure. Brown adipose tissue (BAT) is a major site of mammalian non-shivering thermogenesis or energy dissipation. Thus, modulation of BAT thermogenesis might be a promising application for body weight control and obesity prevention. TRP channels are non-selective calcium-permeable cation channels mainly located on the plasma membrane. As a research focus, TRP channels have been reported to be involved in the thermogenesis of adipose tissue, energy metabolism and body weight regulation. In this review, we will summarize and update the recent progress of the pathological/physiological involvement of TRP channels in adipocyte thermogenesis. Moreover, we will discuss the potential of TRP channels as future therapeutic targets for preventing and combating human obesity and related-metabolic disorders.

Keywords: TRP channels, calcium, thermogenesis, energy metabolism, brown adipocytes, beige adipocytes, obesity

\section{ADIPOSE TISSUES AND OBESITY}

Obesity is a severe public health problem causing various diseases including diabetes, hypertension, coronary heart diseases and cancer, which has received considerable attention as a major public health concern (Nguyen and El-Serag, 2010; Blüher, 2019). According to a prediction based on the data from 1975 to 2014 in 200 countries, the prevalence of global obesity will reach to $18 \%$ for men and 21\% for women by 2025 (NCD Risk Factor Collaboration, 2016). In addition, obesity is becoming prevalent not only in the developed countries, but also in the developing countries (Maharani and Tampubolon, 2016). Therefore, urgent strategies are required for the prevention and reversal of obesity and related metabolic diseases.

Abbreviations: BMI, body mass index; BAT, brown adipose tissue; CT, computed tomography; FDG, fluorodeoxyglucose; HFD, high fat diet; iBAT, interscapular BAT; WAT, white adipose tissue; UCP1, uncoupling protein-1; PET, positron emission tomography; PGCl $\alpha$, peroxisome proliferator-activated receptor gamma coactivator 1-alpha; ROS, reactive oxygen species; TM, trans-membrane; TRP channel, Transient receptor potential channel; TRPV, TRP Vanilloid; TRPV2KO, TRPV2knockout; TRPC, TRP Canonical; TRPM, TRP Melastatin; TRPML, TRP Mucolipin; TRPN, TRP NomPC; TRPP, TRP Polycystin; TRPA, TRP Ankyrin; WT, wild-type; $\left[\mathrm{Ca}^{2+}\right]_{i}$, intracellular $\mathrm{Ca}^{2+}$ levels; $4 \alpha$-PDD, $4 \alpha$-phorbol-12, 13-didecanoate. 
Obesity is accompanied by the imbalance of caloric intake and consumption (Hall and Guo, 2017). There is evidence that adipose tissue is involved in the long-term regulation of energy metabolism and fat quality. Adipose tissue is a highly specialized tissue and plays a key role in energy mobilization regulation (Reilly and Saltiel, 2017; Zhai et al., 2020). Two types of adipose tissue have been found in mammals so far, called white adipose tissue (WAT) and brown adipose tissue (BAT) (Cannon and Nedergaard, 2004; Wu et al., 2020). WAT is generally thought as an organ stores excess energy which maintains energy in the form of triglyceride in lipid droplets. However, a new type of brown-like adipocyte was termed beige/brite adipocyte or inducible brown adipocyte has recently been found in human WAT (Sharp et al., 2012; Cypess et al., 2013; Lidell et al., 2013). BAT, which consumes energy and produce heat rapidly, was first discovered in mammalian hibernation research (Ricquier and Kader, 1976). This thermogenic function is mainly mediated by uncoupling protein-1 (UCP1), a polypeptide that exists in the mitochondrial inner membrane of brown adipocytes (Kajimura et al., 2015; Bertholet et al., 2017; Cannon et al., 2020). It has assessed that BAT thermogenesis was decreased in obese mice by oxygen consumption measurement (Martinez-Botas et al., 2000; Ussher et al., 2010). UCP1 expression level in BAT was decreased in almost all obese animals whereas increased in lean animals (Shirkhani et al., 2018). UCP1 knockout (UCP1KO) mice exhibited obesity phenotypes with increased body fat after six months high fat diet (HFD) feeding (Kontani et al., 2005). On the other hand, cold stimulation and/or $\beta 3$-adrenergic receptor agonist treatment decreased body fat amount by enhancing BAT activity (Lowell and Spiegelman, 2000; Cannon and Nedergaard, 2004). Cold exposure also increased BAT volume and activity, thus increasing energy consumption and promoting weight loss of obese people (Hanssen et al., 2015a,b; Leiria et al., 2019). Several studies have reported that there was a negative correlation between BAT activity/amount and body mass index (BMI) in humans. Imaging data have revealed that patients with higher BMI have lower BAT activity (Cypess et al., 2009; Pfannenberg et al., 2010; Ouellet et al., 2011). Moreover, a single nucleotide substitution at $-3826 \mathrm{~A}$ to $\mathrm{G}$ of UCP1 gene polymorphism has been found in human, which decreased the mRNA expression of Ucp 1 and enhanced the age-related obesity and BAT degradation (Nagai et al., 2007; Yoneshiro et al., 2013). Therefore, BAT might play critical role in the regulation of body weight and energy homeostasis.

\section{THERMOGENESIS IN BROWN AND BEIGE ADIPOCYTES}

BAT was thought to be restricted only in infants (Lean, 1989; Enerback, 2010). However, previous works have reported that BAT was also found in adult humans by using fluorodeoxyglucose (FDG)-positron emission tomography (PET) in combination with computed tomography (CT) techniques (Cypess et al., 2009; van Marken Lichtenbelt et al., 2009). This novel finding highlights the critical role for BAT in the regulation of energy metabolism and fat deposition (Nedergaard and Cannon, 2010; Nedergaard et al., 2011).
Classical brown fat is primarily distributed around interscapular BAT (iBAT), axillary, paravertebral, and perirenal sites (Park et al., 2014). Mitochondria and multilocular lipid droplets were enriched in brown adipocytes, which makes it have remarkable capacity to dissipate energy in the form of heat (Song et al., 2020). UCP1 is expressed in the mitochondria inner membranes of brown adipocytes, which uncouples ATP synthesis from oxidative phosphorylation, thereby dissipating energy as heat. It is well known that BAT non-shivering thermogenesis is controlled directly by sympathetic nervous system innervation and activation. BAT thermogenesis is induced and regulated by the release of norepinephrine from sympathetic nerve terminals and its subsequent binding by $\beta 3$-adrenergic receptors (Nedergaard et al., 2005; Feldmann et al., 2009). Several studies have shown that how UCP1 is activated, and long chain fatty acid is essential for $\mathrm{H}^{+}$transport (Fedorenko et al., 2012). In addition, another proposed mechanism is that mitochondrial reactive oxygen species (ROS) production regulates UCP1 sulfenylation and thermogenesis (Chouchani et al., 2016). However, signaling pathways for thermogenesis in the downstream of $\beta 3$-adrenergic receptor activation still have not been well clarified.

Beige adipocyte (UCP1-positive adipocyte) is known to be surrounded by numerous UCP1-negative adipocytes in human WAT (Wu et al., 2012). Beige adipocytes could be recruited after a short-term cold challenge or treatment with $\beta 3$-adrenergic receptor agonists (Saito et al., 2020). They are very similar to brown adipocytes with high UCP1 expression and thermogenesis (Ye et al., 2013; Li et al., 2014). There are two groups that are a BAT-positive group (subjects have detectable FDG uptake upon cold stimulation) and a BAT-negative group (subjects have undetectable FDG uptake) in humans. Energy metabolism was higher in the BAT-positive group than the BAT-negative group after an acute cold exposure (Orava et al., 2011; Yoneshiro et al., 2011). These studies clearly revealed a critical function for brown and beige adipocytes in cold-induced thermogenesis in humans. Therefore, approaches to modulate brown or beige adipocyte activities might be potential way to prevent and treat human obesity and related metabolic diseases.

\section{TRP CHANNELS}

Transient receptor potential (TRP) ion channels are a major class of calcium-permeable channels, most of which are non-selective cation channels (Montell and Rubin, 1989). TRP channels contain six trans-membrane (TM) domains (TM1-TM6) with a pore loop between TM5 and TM6 (Cao et al., 2013b; Liao et al., 2013; Paulsen et al., 2015; Huynh et al., 2016; Zubcevic et al., 2016). TRP channel superfamily is now subdivided into seven subfamilies and contains 27 channels: TRPV (Vanilloid), TRPC (Canonical), TRPM (Melastatin), TRPML (Mucolipin), TRPN (NomPC), TRPP (Polycystin), and TRPA (Ankyrin) based on their primary amino acid sequences (Ramsey et al., 2006; Wu et al., 2010; Gees et al., 2012). The main signaling pathways in which TRP channels triggered are based on calcium influx through the channels, leading to increases in intracellular $\mathrm{Ca}^{2+}$ levels $\left(\left[\mathrm{Ca}^{2+}\right]_{i}\right)$. Numerous studies have shown that some TRP channels are expressed in adipocytes and are involved in energy 
metabolism and inflammation of adipose tissues, suggesting the potential role of TRP channels in human obesity treatment and prevention (Bishnoi et al., 2018; Uchida et al., 2018; Gao et al., 2019; Zhai et al., 2020). In the present review, we will provide a systematic and brief summary of TRP channels in the regulation of adipocyte thermogenesis and update the recent progress.

\section{TRPV1}

TRPV1 is well-known as a receptor of capsaicin, the pungent ingredient in "hot" chili peppers (Caterina et al., 1997). TRPV1 is activated by a variety of stimuli, including heat (Cao et al., 2013a), protons and capsaicin (Dhaka et al., 2009). In addition, TRPV1 is activated by some compounds in garlic, onion (Salazar et al., 2008), black pepper (Okumura et al., 2010), and other foods, such as gingerol (Iwasaki et al., 2006). TRPV1 has been reported to be expressed in both WAT and BAT (Bishnoi et al., 2013; Kida et al., 2016). TRPV1 expression level is increased in the differentiated HB2 brown adipocytes than in pre-adipocytes (Kida et al., 2016). Moreover, activation of TRPV1 up-regulates the expression of thermogenic genes and induced "browning" in 3T3-L1 adipocytes (Figure 1; Baboota et al., 2014). TRPV1 is expressed in 3T3-L1 pre-adipocytes, adipose tissue of mice and fat tissue of obese humans (Zhang et al., 2007). TRPV1 is activated by dietary capsaicin, a process that induces calcium influx and prevents adipogenesis in 3T3-L1 cells (Zhang et al., 2007) and probably occurs through a calcineurin pathway (Cioffi, 2007). Besides, dietary capsaicin treatment prevented HFDinduced obesity in wild-type (WT) mice in vivo, but not in TRPV1KO mice (Zhang et al., 2007; Chen J. et al., 2015; Chen N. et al., 2015). Moreover, TRPV1 was involved in the regulation of energy intake and glucose homeostasis in WAT during HFDinduced obesity (Lee et al., 2015). Absence of TRPV1 exacerbated obese and insulin resistance associated with HFD and aging (Lee et al., 2015). It has also been reported that monoacylglycerol up-regulated UCP1 expression level in brown adipocytes and suppressed accumulation of visceral fat in mice fed with high fat and sucrose through activation of TRPV1 (Iwasaki et al., 2011). Fish oil intake induced UCP1 up-regulation in both brown and white adipose tissues in a TRPV1 dependent manner (Kim et al., 2015; Lund et al., 2018). Oleoylethanolamide, a newly reported TRPV1 ligand, is also involved in the regulation of energy intake and consumption, feeding behavior and weight control (Laleh et al., 2019).

Human studies have showed that capsaicin ingestion enhanced fat oxidation and energy metabolism during aerobic exercise (Shin and Moritani, 2007). A continuous consumption of chili increased the energy metabolism in the middle-aged subjects (Ahuja et al., 2006). Capsinoids, a non-pungent capsaicin analogs, for continuous 1-3 months also increased energy expenditure and fat oxidation with a reduction in abdominal adiposity in overweight and obese subjects (Inoue et al., 2007; Snitker et al., 2009). Moreover, capsaicin and capsinoids as food ingredients enhanced BAT thermogenesis, subsequently decreased fat mass in humans (Yoneshiro et al., 2012; Saito and Yoneshiro, 2013). An epidemiological study suggested that the energy metabolism was enhanced and the prevalence of human obesity in eastern Asian countries was decreased by increasing the consumption of hot foods containing capsaicin (Wahlqvist and Wattanapenpaiboon, 2001).

It has also been reported that capsaicin injection induced adrenaline secretion, this effect was significantly reduced in TRPV1KO mice (Uchida et al., 2017). Capsaicin directly binds to TRPV1 in gastrointestinal tract, produce afferent signal, subsequently transmit to ventromedial hypothalamic nucleus of central nervous system, and finally send signal to WAT. This could promote the expression of $\beta 2$-adrenoceptor and the production of PRDM16 protein, thus promoting the generation of beige adipocytes, resulting in increased systemic energy expenditure (Ohyama et al., 2016; Saito et al., 2020). Catechins in green tea may activate and recruit BAT by acting on TRPV1/TRPA1 of gastrointestinal sensory neurons in the same way as capsaicin (Mako et al., 2015). Besides, topical application of capsaicin cream in mice resulted in weight loss and adipose tissue weight (Lee et al., 2013). However, whether the regulatory effect of topical capsaicin on obesity is through TRPV1 to activate central nervous system remains to be further studied. These studies clearly demonstrated that targeting TRPV1 and modulation its activity with capsaicin and analogs could be effective approaches for human obesity treatment and prevention, although the anti-obesity effect of TRPV1 activation may be involved not only in adipose tissue, but also in nervous system.

\section{TRPV2}

TRPV2 was initially reported to be activated by noxious heat with an activation temperature threshold of higher than $52^{\circ} \mathrm{C}$ (Caterina et al., 1999) and found to be activated by several chemicals, e.g., 2-aminoethoxydiphenyl borate (2APB) and lysophosphatidylcholine (LPC) (Juvin et al., 2007; Monet et al., 2009). TRPV2 was also reported to be activated by mechanical stimulation and/or cell swelling (Muraki et al., 2003; Iwata et al., 2009). TRPV2 is expressed in both WAT and BAT (Sun et al., 2017a). TRPV2 is highly expressed in mouse brown adipocytes compared with TRPV1, TRPV3, TRPV4 and TRPM8 (Sun et al., 2016a,b). The expression of TRPV2 was up-regulated at mRNA, protein and functional levels in the differentiated brown adipocytes (Sun et al., 2016b, 2017b). Primary TRPV2-deficient (TRPV2KO) adipocytes show decreased mRNA levels of multiple genes involved in mitochondrial oxidative metabolism, such as Ucp1 and peroxisome proliferator-activated receptor gamma coactivator 1-alpha $(P g c 1 \alpha)$. Besides, TRPV2KO adipocytes showed decreased responses to a $\beta$-adrenergic receptor agonist, isoproterenol, which might be due to the lack of TRPV2mediated calcium influx. These results suggested that TRPV2mediated calcium influx is involved in thermogenic gene induction upon $\beta$-adrenergic receptor activation (Figure 1). TRPV2KO mice showed cold intolerance and significantly smaller increases in Ucp 1 mRNA and protein upon cold stimulation at $4^{\circ} \mathrm{C}$ without changes in their activities. On the other hand, sympathetic nerve activity was not changed in TRPV2KO mice. TRPV2KO mice showed impaired iBAT adaptive thermogenesis upon administration of a $\beta 3$-adrenergic 

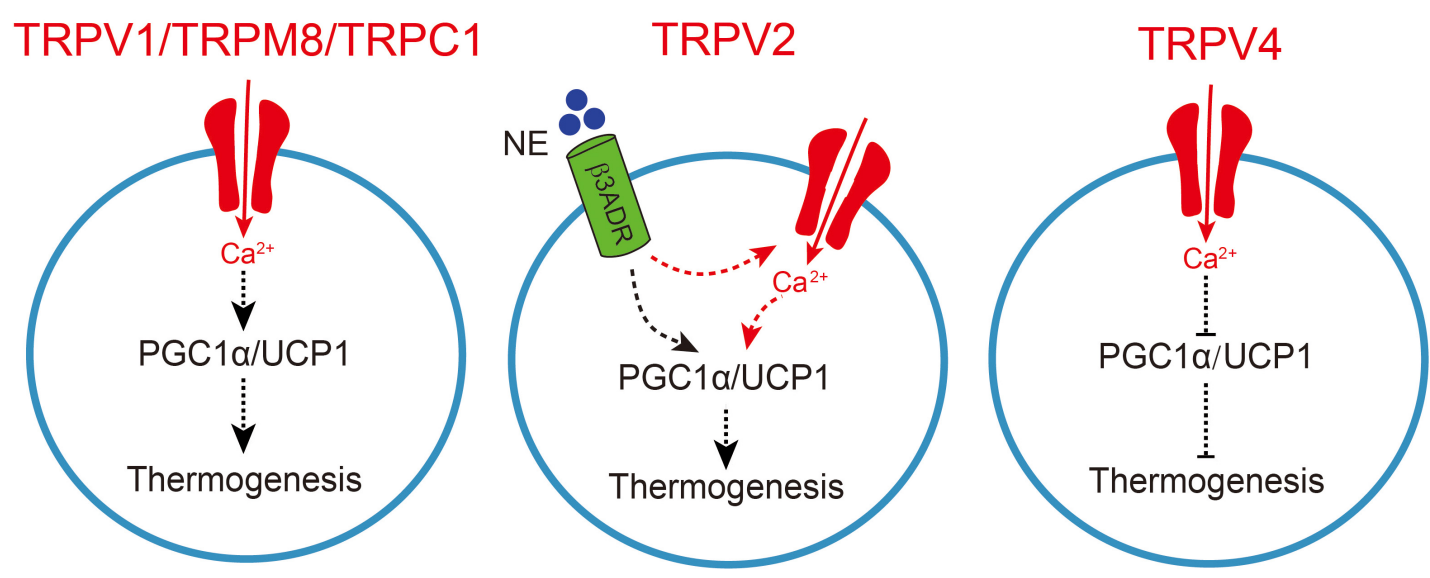

FIGURE 1 | TRP channel-mediated adipocyte thermogenesis. A schematic figure of how TRPV1, TRPV2, TRPV4, TRPM8, and TRPC1-mediated calcium influx regulates thermogenic gene expression in adipocytes, which causes enhanced thermogenesis. Moreover, the increase in sympathetic nerve activity causes norepinephrine release from the sympathetic nerves and activation of $\beta 3$-adrenergic receptor ( $\beta 3 A D R$ ) in brown adipocytes, TRPV2 synergistically collaborated with $\beta 3 A D R$ to involve in the regulation of peroxisome proliferator-activated receptor gamma coactivator-1 a (PGC1a) and uncoupling protein 1 (UCP1), subsequently enhances thermogenesis. On the other hand, TRPV4-mediated calcium influx negatively regulates thermogenic gene expression in adipocytes and subsequently inhibits thermogenesis.

receptor agonist, BRL37344. Importantly, TRPV2KO mice had significant increases in body weight and adipose tissues upon a HFD treatment (Sun et al., 2016a). Up-regulation of TRPV2 was also observed in obese and diabetic (db/db) mice (Sun et al., 2016a, 2017a). It has also been reported that tart cherry may attenuate adipogenesis by acting directly on the adipose tissue and down-regulating the HFD-induced mRNA expression of TRPV1 and TRPV2 (Cocci et al., 2021). These findings suggested that TRPV2 might be contributed to adipocyte thermogenesis. However, it is necessary to further examine the expression and function of TRPV2 in human BAT and develop specific ligands of TRPV2.

\section{TRPV3}

TRPV3 is a member of the TRPV subfamily which is different from TRPV1 and TRPV2. TRPV3 is well-known to be activated by innocuous temperature around body temperature but initially activated by a high noxious threshold which is over $50^{\circ} \mathrm{C}$ (Liu and Qin, 2017). The chemical agonists of TRPV3 include camphor, carvacrol, (-)-epicatechin, 2APB, and endogenous ligand farnesyl pyrophosphate (Cheung et al., 2015; Broad et al., 2016). TRPV3 could form heteromeric channels with TRPV1 (Cheng et al., 2012), which also involves in the regulation of adipogenesis and HFD-induced obesity (Cheung et al., 2015). TRPV3 has been reported to be expresses in BAT and WAT (Bishnoi et al., 2013). The expression of TRPV3 was dramatically down-regulated in visceral adipose tissue of obesity mice, including HFD-induced obesity mice, ob/ob and db/db mice (Cheung et al., 2015; Sun et al., 2017a). HFD feeding up-regulated TRPV3 in the medial nucleus tractus solitaries and hypoglossal nucleus, which is accompanied by a reduced expression of proopiomelanocortin and resulted in increased food intake and a gain of bodyweight (Hu et al., 2011). Activation of TRPV3 by (-)-epicatechin prevented adipogenesis in 3T3-L1 preadipocytes and played an anti-adipogenic role in vivo (Cheung et al., 2015). Besides, berberine alleviates olanzapine-induced obesity by targeting TRPV1/TRPV3 in hypothalamus of mice (Singh et al., 2020). These studies suggested that targeting TRPV3 could be an intriguing approach for the treatment and prevention of obesity. However, the expression of TRPV3 and its role in human obesity needs further exploration.

\section{TRPV4}

TRPV4 was reported to be activated by osmolarity changes or mechanical stimuli (Liedtke et al., 2000; Strotmann et al., 2000; Watanabe et al., 2002a). TRPV4 is also activated by diverse chemical compounds, including a synthetic phorbol ester,

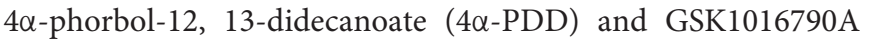
(Watanabe et al., 2002b; Willette et al., 2008) as well as moderate warmth (temperature threshold higher than $27^{\circ} \mathrm{C}$ ) (Guler et al., 2002; Watanabe et al., 2002b). TRPV4 is expressed in BAT and WAT as well (Sun et al., 2017a, 2020; Uchida et al., 2018). It has been reported that insulin regulates TRPV4-mediated metabolic homeostasis in human white adipocytes (Sanchez et al., 2016). TRPV4 is involved in the modulation of thermogenic and inflammatory pathways in adipose tissue. Knockdown of TRPV4 enhanced the basal and norepinephrine-induced induction of the expression of Pgcla and Ucp1 (Ye et al., 2012). ERK1/2 were reported to be activated by TRPV4-mediated calcium signaling (Thodeti et al., 2009), and TRPV4 activation-induced calcium influx caused a rapid phosphorylation of ERK1/2 and JNK1/2, which further suppressed the expression of thermogenic genes in 3T3-F442A adipocytes (Figure 1; Ye et al., 2012). Knockdown of TRPV4 also reduced adipose tissue inflammation by inhibiting a number of pro-inflammatory genes (Ye et al., 2012). The expression of TRPV4 in WAT was higher than that in BAT (Sun et al., 2017a). The significant up-regulation of thermogenic gene expression upon TRPV4 inhibition led to the 
occurrence of WAT "browning” (Ye et al., 2012). TRPV4KO mice exhibited increased muscle energy oxidation and resistance to HFD-induced obese in mice (Kusudo et al., 2012). It has also been reported that treadmill running and rutin ameliorate HFDinduced obesity in mice by suppressing the expression of TRPV4 in adipocytes (Chen N. et al., 2015). Besides, dietary intervention in obese dams protects male offspring from WAT induction of TRPV4, adiposity, and hyperinsulinemia (Janoschek et al., 2016). A human subject-based study has revealed that polymorphisms of TRPV4 gene affects BMI and body fat mass in subjects in Taiwan (Duan et al., 2015). These results revealed an opposite role of TRPV4 in the modulation of adipocyte thermogenesis without knowing the potential mechanisms. Examine the expression and function of TRPV4 in human obesity and developing TRPV4 specific antagonist and in vivo examination of the new compounds is warranted.

\section{TRPM8}

The TRPM subfamily consists of eight different subunits, TRPM1 to TRPM8 (Boesmans et al., 2011). TRPM8 is wellknown as a menthol receptor which has been reported in the year of 2002 (McKemy et al., 2002). In a human adipocyte cell line, menthol-induced TRPM8 activation increased UCP1 expression, mitochondrial activation and heat production (Figure 1; Rossato et al., 2014). The mRNA and protein expression levels of TRPM8 are significantly increased in the differentiated adipocytes, suggesting the importance of TRPM8 for adipocyte thermogenesis (Rossato et al., 2014). In cultured adipocytes, menthol induced an up-regulation of UCP1 expression which may through a protein kinase A pathway, which subsequently increases BAT thermogenesis and WAT "browning" (Ma et al., 2012; Jiang et al., 2017; Sanders et al., 2020). Besides, it has been reported that cold-sensing TRPM8 channel participates in the regulation of clock and clock-controlled genes in BAT thermogenesis (Moraes et al., 2017). Bioavailable menthol induces energy expending phenotype in differentiating adipocytes (Khare et al., 2019). In vivo studies have revealed that dietary menthol supplementation dramatically increased the core body temperatures and locomotor activity in WT mice, but not in TRPM8KO and UCP1KO mice. Menthol supplementation in diet alleviated HFD-induced obesity and insulin resistance as well (Ma et al., 2012; Jiang et al., 2017). And the preventive effect of menthol against HFD-induced obesity and related complications probably involve a glucagon mechanism (Khare et al., 2018). These results suggested that activation of TRPM8 could enhance BAT thermogenesis, which paves a new approach for the treatment and prevention of obesity. TRPM8-dependent increase in core body temperature upon a menthol treatment or cold exposure, which may be mediated by a UCP1 up-regulation (Tajino et al., 2011). Intragastric administration of menthol also enhanced BAT thermogenesis in vivo (Tajino et al., 2007; Masamoto et al., 2009). In addition, TRPM8 polymorphism has been reported to be closely correlated with metabolic syndrome in Turkish population (Tabur et al., 2015). Topical menthol appears to increase core body temperature and metabolic rate in adults (Valente et al., 2015). In summary, activation of TRPM8 by its ligands, such as menthol and icilin, mimics adipocyte thermogenesis and might constitute a promising approach to prevent overweight and obesity. However, randomized clinical trials of topical menthol in obese patients are necessary.

\section{TRPA1}

TRPA1 was initially reported as a noxious cold-activated channel with a temperature threshold around $17^{\circ} \mathrm{C}$ (Story et al., 2003), However, later studies have initiated a heated debate over the role of TRPA1 as a cold sensor. But its cold sensitivity has been disputed later, and the contribution of TRPA1 to cold sensing is currently a matter of strong debate (Bautista et al., 2006; Talavera et al., 2020). TRPA1 is potentially activated by several food components, like allyl isothiocyanate, icilin, menthol, cinnamaldehyde and capsinoids (Laursen et al., 2015). TRPA1 is involved in adipocyte thermogenesis and energy metabolism (Watanabe and Terada, 2015). In HFD-induced obesity mice, oral administration of allyl isothiocyanate reduces body weight, accumulation of lipid droplets in the liver, and white adipocyte size (Lo et al., 2018). It has been reported that cinnamaldehyde reduces visceral fat deposition in HFDtreated mice by stimulating BAT between scapulae (Tamura et al., 2012). Cinnamaldehyde activates TRPA 1 in mouse gastric epithelial cells and up-regulates fatty acid oxidation-related genes in adipose tissue (Camacho et al., 2015). Oleuropein aglycone, as an agonist of TRPA1 and TRPV1, enhances the expression of UCP1 in BAT and promote fat thermogenesis by promoting the secretion of norepinephrine (Oi-Kano et al., 2016). It has been hypothesized that menthol-induced thermogenesis in adipocyte probably involved a TRPA1 mechanism as well (Sakellariou et al., 2016). Moreover, TRPA1 activation induces adrenaline secretion and prevent fat accumulation and obese in rodents (Watanabe and Terada, 2015). Intravenous injection of AITC induces adrenaline secretion, and adrenaline promotes the thermogenesis of BAT by activating $\beta 3$-adrenergic receptor (Saito et al., 2020). These studies suggested that TRPA1 regulates heat production of BAT through central nervous system (Zsombok and Derbenev, 2016). Therefore, activation of TRPA1 by its ligands might be a promising approach for human obesity treatment and prevention. However, the anti-obesity mechanism which TRPA1 and its ligands involved need further exploration. Randomized clinical trials of TRPA1 activation in obese patients are warranted as well.

\section{TRPC1 AND TRPC5}

TRPC subfamily includes seven members (TRPC1-7). TRPC channels are usually formed by homo- or heteromeric TRPC proteins (Huang et al., 2011). There is no evidence demonstrate TRPC channels have thermosensitive property so far. TRPC1 is highly expressed in adipocyte depots including BAT and that TRPC1-deficient mice are prone to weight gain and manifest reduced metabolic control (Wolfrum et al., 2018). TRPC1 regulates brown adipocyte activity in a PPAR $\gamma$-dependent manner, suggesting that TRPC1 is a downstream component 
of a mechanism that translates metabolic or environmental stimuli into output in the form of BAT activity (Figure 1; Wolfrum et al., 2018). However, an opposite observation has been reported that fat mass and fasting glucose concentrations were lower in TRPC1KO mice that were fed a HFD (45\% fat) (Krout et al., 2017). Besides, a mechanically activated TRPC1like current in white adipocytes was observed (El Hachmane and Olofsson, 2018). It has been reported that either knockdown of TRPC1/TRPC5 in vitro or conditional knockout of TRPC5 in vivo has increased adiponectin generation in mouse (Sukumar et al., 2012). In addition, both exogenous and endogenous pituitary adenylate cyclase activating polypeptides stimulate proopiomelanocortin neurons and increase energy consumption by activating TRPC1 and TRPC5 channels, which suggests that it is possible to promote BAT thermogenesis by activating TRPC1/TRPC5 in central nervous system (Chang et al., 2020). These studies demonstrated the involvement of TRPC1/TRPC5 in the regulation of energy homeostasis. Further examination of the expression of TRPC1/TRPC5 in human adipose tissues and developing TRPC1/TRPC5 specific agonist are needed.

\section{TRPP}

TRPP is a type of non-selective ion channel, which has been proved to be associated with autosomal dominant polycystic kidney (Moran et al., 2004). TRPP has three family members, TRPP2, TRPP3, and TRPP5. TRPP2, also known as PKD2 or polycystin-2, has been reported to be expressed in adipose tissue, and the expression level of TRPP2 in mature adipocytes is higher than in pre-adipocytes (Moran et al., 2004; Sukumar et al., 2012). Knockdown of TRPP3 suppresses the expression of UCP1 and PGC1 $\alpha$, and attenuates the mitochondrial respiration in adipocytes but has not affected adipogenesis (Goralczyk et al., 2017). These results revealed that TRPP3 might be involved in adipocyte thermogenesis. Further analysis of the mechanisms of TRPP channels in adipocyte thermogenesis is necessary.

\section{CONCLUSION AND PERSPECTIVES}

In the past decades, TRP channels have been widely studied in adipocyte thermogenesis, adipogenesis, adipose tissue inflammation, and obesity. TRP channels have been

\section{REFERENCES}

Ahuja, K. D., Robertson, I. K., Geraghty, D. P., and Ball, M. J. (2006). Effects of chili consumption on postprandial glucose, insulin, and energy metabolism. Am. J. Clin. Nutr. 84, 63-69.

Baboota, R. K., Singh, D. P., Sarma, S. M., Kaur, J., Sandhir, R., Boparai, R. K., et al. (2014). Capsaicin induces "brite" phenotype in differentiating 3T3-L1 preadipocytes. PLoS One 9:e103093. doi: 10.1371/journal.pone.0103093

Bautista, D. M., Jordt, S. E., Nikai, T., Tsuruda, P. R., Read, A. J., Poblete, J., et al. (2006). TRPA1 mediates the inflammatory actions of environmental irritants and proalgesic agents. Cell 124, 1269-1282. doi: 10.1016/j.cell.2006.02.023

Bertholet, A. M., Kazak, L., Chouchani, E. T., Bogaczynska, M. G., Paranjpe, I., Wainwright, G. L., et al. (2017). Mitochondrial Patch Clamp of Beige Adipocytes Reveals UCP1-Positive and UCP1-Negative Cells Both Exhibiting demonstrated to play critical roles in the regulation of energy metabolism for the treatment and prevention of human obesity. In the present review, we summarized and updated the recent progress of the involvement of several TRP channels in adipocyte thermogenesis. It's worth noting that several concerns still need to be further explored. First of all, the underlying mechanisms which TRP channel-mediated in the thermogenesis process of adipocytes are still controversial, which need to be clearly addressed. Secondly, novel specific ligands of TRP channels are warranted to be developed since there is no specific ligands for TRP channels so far. Thirdly, how do TRP channels exert tissuespecific effects in adipose tissues? These issues are warranted to be addressed by further animal and clinical studies in the future. In conclusion, targeting TRP channels could be promising strategies for clinical treatment and prevention of human obesity and related-metabolic diseases.

\section{AUTHOR CONTRIBUTIONS}

WS, ST, YL, FZ, and TZ were involved in literature collection, summarization, and written the review manuscript. All authors contributed to the article and approved the submitted version.

\section{FUNDING}

This work was supported by grants from the National Natural Science Foundation of China (No. 81700741), Medical Science and Technology Foundation of Guangdong (A2020600), the Science and Technology Project of Shenzhen (No. 20190808300180), Shenzhen Municipal Science, Technology and Innovation Commission (No. JCYJ20180302144710880), and Chongqing Health Joint Medical Research Project (No. 2020MSXM112).

\section{ACKNOWLEDGMENTS}

We are grateful to Makoto Tominaga (National Institute for Physiological Sciences) and Kunitoshi Uchida (Fukuoka Dental College of Japan) for their kind suggestions and comments.

Futile Creatine Cycling. Cell Metab. 25, 811-822e814. doi: 10.1016/j.cmet.2017. 03.002

Bishnoi, M., Khare, P., Brown, L., and Panchal, S. K. (2018). Transient receptor potential (TRP) channels: a metabolic TR(i)P to obesity prevention and therapy. Obes. Rev. 19, 1269-1292. doi: 10.1111/obr.12703

Bishnoi, M., Kondepudi, K. K., Gupta, A., Karmase, A., and Boparai, R. K. (2013). Expression of multiple Transient Receptor Potential channel genes in murine 3T3-L1 cell lines and adipose tissue. Pharmacol. Rep. 65, 751-755. doi: 10.1016/ s1734-1140(13)71055-7

Blüher, M. (2019). Obesity: global epidemiology and pathogenesis. Nat. Rev. Endocrinol. 15, 288-298.

Boesmans, W., Owsianik, G., Tack, J., Voets, T., and Vanden Berghe, P. (2011). TRP channels in neurogastroenterology: opportunities for therapeutic intervention. Br. J. Pharmacol. 162, 18-37. doi: 10.1111/j.1476-5381.2010.01009.x 
Broad, L. M., Mogg, A. J., Eberle, E., Tolley, M., Li, D. L., and Knopp, K. L. (2016). TRPV3 in Drug Development. Pharmaceuticals 9:h9030055. doi: 10. $3390 /$ ph9030055

Camacho, S., Michlig, S., de Senarclens-Bezençon, C., Meylan, J., Meystre, J., Pezzoli, M., et al. (2015). Anti-Obesity and Anti-Hyperglycemic Effects of Cinnamaldehyde via altered Ghrelin Secretion and Functional impact on Food Intake and Gastric Emptying. Sci. Rep. 5:7919.

Cannon, B., and Nedergaard, J. (2004). Brown adipose tissue: function and physiological significance. Physiol. Rev. 84, 277-359. doi: 10.1152/physrev. 00015.2003

Cannon, B., de Jong, J. M. A., Fischer, A. W., Nedergaard, J., and Petrovic, N. (2020). Human brown adipose tissue: Classical brown rather than brite/beige? Exp. Physiol. 105, 1191-1200. doi: 10.1113/EP087875

Cao, E., Cordero-Morales, Julio, F., Liu, B., Qin, F., and Julius, D. (2013a). TRPV1 channels are intrinsically heat sensitive and negatively regulated by phosphoinositide lipids. Neuron 77, 667-679.

Cao, E., Liao, M., Cheng, Y., and Julius, D. (2013b). TRPV1 structures in distinct conformations reveal activation mechanisms. Nature 504, 113-118. doi: 10. 1038/nature12823

Caterina, M. J., Rosen, T. A., Tominaga, M., Brake, A. J., and Julius, D. (1999). A capsaicin-receptor homologue with a high threshold for noxious heat. Nature 398, 436-441. doi: 10.1038/18906

Caterina, M. J., Schumacher, M. A., Tominaga, M., Rosen, T. A., Levine, J. D., and Julius, D. (1997). The capsaicin receptor: a heat-activated ion channel in the pain pathway. Nature 389, 816-824. doi: 10.1038/39807

Chang, R., Hernandez, J., Gastelum, C., Guadagno, K., and Wagner, E. J. (2020). Pituitary Adenylate Cyclase Activating Polypeptide Excites Proopiomelanocortin Neurons: Implications for the Regulation of Energy Homeostasis. Neuroendocrinology 111, 45-69.

Chen, J., Li, L., Li, Y., Liang, X., Sun, Q., Yu, H., et al. (2015). Activation of TRPV1 channel by dietary capsaicin improves visceral fat remodeling through connexin43-mediated Ca2+ influx. Cardiovasc. Diabetol. 14:22. doi: 10.1186/ s12933-015-0183-6

Chen, N., Cheng, J., Zhou, L., Lei, T., Chen, L., Shen, Q., et al. (2015). Effects of treadmill running and rutin on lipolytic signaling pathways and TRPV4 protein expression in the adipose tissue of diet-induced obese mice. J. Physiol. Biochem. 71, 733-742. doi: 10.1007/s13105-015-0437-5

Cheng, W., Yang, F., Liu, S., Colton, C. K., Wang, C., Cui, Y., et al. (2012). Heteromeric heat-sensitive transient receptor potential channels exhibit distinct temperature and chemical response. J. Biol. Chem. 287, 7279-7288. doi: $10.1074 /$ jbc.M111.305045

Cheung, S. Y., Huang, Y., Kwan, H. Y., Chung, H. Y., and Yao, X. (2015). Activation of transient receptor potential vanilloid 3 channel (TRPV3) suppresses adipogenesis. Endocrinology 156, 2074-2086. doi: 10.1210/en.2014-1831

Chouchani, E. T., Kazak, L., Jedrychowski, M. P., Lu, G. Z., Erickson, B. K., Szpyt, J., et al. (2016). Mitochondrial ROS regulate thermogenic energy expenditure and sulfenylation of UCP1. Nature 532, 112-116. doi: 10.1038/nature17399

Cioff, D. L. (2007). The skinny on TRPV1. Circ. Res. 100, 934-936. doi: 10.1161/ 01.RES.0000265139.10277.62

Cocci, P., Moruzzi, M., Martinelli, I., Maggi, F., Micioni, Di Bonaventura, M. V., et al. (2021). Tart cherry (Prunus cerasus L.) dietary supplement modulates visceral adipose tissue $\mathrm{CB} 1 \mathrm{mRNA}$ levels along with other adipogenesis-related genes in rat models of diet-induced obesity. Eur. J. Nutr. 2021:2459-y. doi: 10.1007/s00394-020-02459-y

Cypess, A. M., Lehman, S., Williams, G., Tal, I., Rodman, D., Goldfine, A. B., et al. (2009). Identification and importance of brown adipose tissue in adult humans. N. Engl. J. Med. 360, 1509-1517. doi: 10.1056/NEJMoa0810780

Cypess, A. M., White, A. P., Vernochet, C., Schulz, T. J., Xue, R., Sass, C. A., et al. (2013). Anatomical localization, gene expression profiling and functional characterization of adult human neck brown fat. Nat. Med. 19, 635-639. doi: $10.1038 / \mathrm{nm} .3112$

Dhaka, A., Uzzell, V., Dubin, A. E., Mathur, J., Petrus, M., Bandell, M., et al. (2009). TRPV1 is activated by both acidic and basic pH. J. Neurosci. 29, 153-158.

Duan, D. M., Wu, S., Hsu, L. A., Teng, M. S., Lin, J. F., Sun, Y. C., et al. (2015). Associations between TRPV4 genotypes and body mass index in Taiwanese subjects. Mol. Genet. Genomics 290, 1357-1365. doi: 10.1007/s00438-0150996-8
El Hachmane, M. F., and Olofsson, C. S. (2018). A mechanically activated TRPC1like current in white adipocytes. Biochem. Biophys. Res. Commun. 498, 736-742. doi: 10.1016/j.bbrc.2018.03.050

Enerback, S. (2010). Human brown adipose tissue. Cell Metab. 11, 248-252. doi: 10.1016/j.cmet.2010.03.008

Fedorenko, A., Lishko, P. V., and Kirichok, Y. (2012). Mechanism of fatty-aciddependent UCP1 uncoupling in brown fat mitochondria. Cell 151, 400-413. doi: 10.1016/j.cell.2012.09.010

Feldmann, H. M., Golozoubova, V., Cannon, B., and Nedergaard, J. (2009). UCP1 ablation induces obesity and abolishes diet-induced thermogenesis in mice exempt from thermal stress by living at thermoneutrality. Cell Metab. 9, 203-209. doi: 10.1016/j.cmet.2008.12.014

Gao, P., Yan, Z., and Zhu, Z. (2019). The role of adipose TRP channels in the pathogenesis of obesity. J. Cell. Physiol. 234, 12483-12497.

Gees, M., Owsianik, G., Nilius, B., and Voets, T. (2012). TRP channels. Compr. Physiol. 2, 563-608. doi: 10.1002/cphy.c110026

Goralczyk, A., van Vijven, M., Koch, M., Badowski, C., Yassin, M. S., Toh, S. A., et al. (2017). TRP channels in brown and white adipogenesis from human progenitors: new therapeutic targets and the caveats associated with the common antibiotic, streptomycin. FASEB J. 31, 3251-3266. doi: 10.1096/ fj.201601081RR

Guler, A. D., Lee, H., Iida, T., Shimizu, I., Tominaga, M., and Caterina, M. (2002). Heat-evoked activation of the ion channel, TRPV4. J. Neurosci. 22, 6408-6414

Hall, K. D., and Guo, J. (2017). Obesity Energetics: Body Weight Regulation and the Effects of Diet Composition. Gastroenterology 152:1718.

Hanssen, M. J. W., Hoeks, J., Brans, B., van der Lans, A. A. J. J., Schaart, G., van den Driessche, J. J., et al. (2015a). Short-term cold acclimation improves insulin sensitivity in patients with type 2 diabetes mellitus. Nat. Med. 21, 863-865.

Hanssen, M. J. W., Lans, A. A. J. J. V. D., Brans, B., Hoeks, J., Jardon, K. M. C., Schaart, G., et al. (2015b). Short-term Cold Acclimation Recruits Brown Adipose Tissue in Obese Humans. Diabetes 65, $1179-1189$.

Hu, J., Choo, H. J., and Ma, S. X. (2011). Infrared heat treatment reduces food intake and modifies expressions of TRPV3-POMC in the dorsal medulla of obesity prone rats. Int. J. Hyperthermia 27, 708-716. doi: 10.3109/02656736. 2011.601283

Huang, J., Du, W., Yao, H., and Wang, Y. (2011). "TRPC Channels in Neuronal Survival," in TRP Channels, ed. M. X. Zhu (Boca Raton, FL: CRC Press).

Huynh, K. W., Cohen, M. R., Jiang, J., Samanta, A., Lodowski, D. T., Zhou, Z. H., et al. (2016). Structure of the full-length TRPV2 channel by cryo-EM. Nat. Commun. 7:11130. doi: 10.1038/ncomms11130

Inoue, N., Matsunaga, Y., Satoh, H., and Takahashi, M. (2007). Enhanced energy expenditure and fat oxidation in humans with high BMI scores by the ingestion of novel and non-pungent capsaicin analogues (capsinoids). Biosci. Biotechnol. Biochem. 71, 380-389. doi: 10.1271/bbb.60341

Iwasaki, Y., Morita, A., Iwasawa, T., Kobata, K., Sekiwa, Y., Morimitsu, Y., et al. (2006). A nonpungent component of steamed ginger-[10]-shogaol-increases adrenaline secretion via the activation of TRPV1. Nutrit. Neurosci. 9, 169-178.

Iwasaki, Y., Tamura, Y., Inayoshi, K., Narukawa, M., Kobata, K., Chiba, H., et al. (2011). TRPV1 agonist monoacylglycerol increases UCP1 content in brown adipose tissue and suppresses accumulation of visceral fat in mice fed a high-fat and high-sucrose diet. Biosci. Biotechnol. Biochem. 75, 904-909. doi: 10.1271/ bbb. 100850

Iwata, Y., Katanosaka, Y., Arai, Y., Shigekawa, M., and Wakabayashi, S. (2009). Dominant-negative inhibition of Ca2+ influx via TRPV2 ameliorates muscular dystrophy in animal models. Hum. Mol. Genet. 18, 824-834. doi: 10.1093/hmg/ ddn 408

Janoschek, R., Bae-Gartz, I., Vohlen, C., Alcazar, M. A., Dinger, K., Appel, S., et al. (2016). Dietary intervention in obese dams protects male offspring from WAT induction of TRPV4, adiposity, and hyperinsulinemia. Obesity 24, 1266-1273. doi: 10.1002/oby.21486

Jiang, C., Zhai, M., Yan, D., Li, D., Li, C., Zhang, Y., et al. (2017). Dietary mentholinduced TRPM8 activation enhances WAT "browning" and ameliorates dietinduced obesity. Oncotarget 8, 75114-75126. doi: 10.18632/oncotarget.20540

Juvin, V., Penna, A., Chemin, J., Lin, Y. L., and Rassendren, F. A. (2007). Pharmacological characterization and molecular determinants of the activation of transient receptor potential V2 channel orthologs by 2-aminoethoxydiphenyl borate. Mol. Pharmacol. 72, 1258-1268. doi: 10.1124/mol.107.037044 
Kajimura, S., Spiegelman, B. M., and Seale, P. (2015). Brown and Beige Fat: Physiological Roles beyond Heat Generation. Cell Metab. 22, 546-559. doi: 10.1016/j.cmet.2015.09.007

Khare, P., Chauhan, A., Kumar, V., Kaur, J., Mahajan, N., Kumar, V., et al. (2019). Bioavailable Menthol (Transient Receptor Potential Melastatin-8 Agonist) Induces Energy Expending Phenotype in Differentiating Adipocytes. Cells 8:cells8050383. doi: 10.3390/cells8050383

Khare, P., Mangal, P., Baboota, R. K., Jagtap, S., Kumar, V., Singh, D. P., et al. (2018). Involvement of Glucagon in Preventive Effect of Menthol Against High Fat Diet Induced Obesity in Mice. Front. Pharmacol. 9:1244. doi: 10.3389/fphar. 2018.01244

Kida, R., Yoshida, H., Murakami, M., Shirai, M., Hashimoto, O., Kawada, T., et al. (2016). Direct action of capsaicin in brown adipogenesis and activation of brown adipocytes. Cell Biochem. Funct. 34, 34-41. doi: 10.1002/cbf.3162

Kim, M., Goto, T., Yu, R., Uchida, K., Tominaga, M., Kano, Y., et al. (2015). Fish oil intake induces UCP1 upregulation in brown and white adipose tissue via the sympathetic nervous system. Sci. Rep. 5:18013. doi: 10.1038/srep18013

Kontani, Y., Wang, Y., Kimura, K., Inokuma, K. I., Saito, M., Suzuki-Miura, T., et al. (2005). UCP1 deficiency increases susceptibility to diet-induced obesity with age. Aging Cell 4, 147-155. doi: 10.1111/j.1474-9726.2005.00157.x

Krout, D., Schaar, A., Sun, Y., Sukumaran, P., Roemmich, J. N., Singh, B. B., et al. (2017). The TRPC1 Ca(2+)-permeable channel inhibits exercise-induced protection against high-fat diet-induced obesity and type II diabetes. J. Biol. Chem. 292, 20799-20807. doi: 10.1074/jbc.M117.809954

Kusudo, T., Wang, Z., Mizuno, A., Suzuki, M., and Yamashita, H. (2012). TRPV4 deficiency increases skeletal muscle metabolic capacity and resistance against diet-induced obesity. J. Appl. Physiol. 112, 1223-1232. doi: 10.1152/ japplphysiol.01070.2011

Laleh, P., Yaser, K., and Alireza, O. (2019). Oleoylethanolamide: A novel pharmaceutical agent in the management of obesity-an updated review. J. Cell. Physiol. 234, 7893-7902.

Laursen, W. J., Anderson, E. O., Hoffstaetter, L. J., Bagriantsev, S. N., and Gracheva, E. O. (2015). Species-specific temperature sensitivity of TRPA1. Temperature 2, 214-226. doi: 10.1080/23328940.2014.1000702

Lean, M. E. (1989). Brown adipose tissue in humans. Proc. Nutr. Soc. 48, 243-256. doi: $10.1079 /$ pns 19890036

Lee, E., Jung, D. Y., Kim, J. H., Patel, P. R., Hu, X., Lee, Y., et al. (2015). Transient receptor potential vanilloid type-1 channel regulates diet-induced obesity, insulin resistance, and leptin resistance. FASEB J. 29, 3182-3192. doi: 10.1096/fj.14-268300

Lee, G. R., Shin, M. K., Yoon, D. J., Kim, A. R., Yu, R., Park, N. H., et al. (2013). Topical application of capsaicin reduces visceral adipose fat by affecting adipokine levels in high-fat diet-induced obese mice. Obesity 21, 115-122.

Leiria, L. O., Wang, C. H., Lynes, M. D., Yang, K., and Tseng, Y. H. (2019). 12-Lipoxygenase Regulates Cold Adaptation and Glucose Metabolism by Producing the Omega-3 Lipid 12-HEPE from Brown Fat. Cell Metabol. 30, 768.e-783.e.

Li, Y., Fromme, T., Schweizer, S., Schottl, T., and Klingenspor, M. (2014). Taking control over intracellular fatty acid levels is essential for the analysis of thermogenic function in cultured primary brown and brite/beige adipocytes. EMBO Rep. 15, 1069-1076. doi: 10.15252/embr.201438775

Liao, M., Cao, E., Julius, D., and Cheng, Y. (2013). Structure of the TRPV1 ion channel determined by electron cryo-microscopy. Nature 504, 107-112. doi: 10.1038 /nature 12822

Lidell, M. E., Betz, M. J., Dahlqvist Leinhard, O., Heglind, M., Elander, L., Slawik, M., et al. (2013). Evidence for two types of brown adipose tissue in humans. Nat. Med. 19, 631-634. doi: 10.1038/nm.3017

Liedtke, W., Choe, Y., Marti-Renom, M. A., Bell, A. M., Denis, C. S., Sali, A., et al (2000). Vanilloid receptor-related osmotically activated channel (VR-OAC), a candidate vertebrate osmoreceptor. Cell 103, 525-535.

Liu, B., and Qin, F. (2017). Single-residue molecular switch for high-temperature dependence of vanilloid receptor TRPV3. Proc. Natl. Acad. Sci. U S A. 114, 1589-1594. doi: 10.1073/pnas.1615304114

Lo, C. W., Chen, C. S., Chen, Y. C., Hsu, Y. A., Huang, C. C., Chang, C. Y., et al. (2018). Allyl Isothiocyanate Ameliorates Obesity by Inhibiting Galectin-12. Mol. Nutr. Food Res. 62:e1700616. doi: 10.1002/mnfr.201700616

Lowell, B. B., and Spiegelman, B. M. (2000). Towards a molecular understanding of adaptive thermogenesis. Nature 404, 652-660. doi: 10.1038/35007527
Lund, J., Larsen, L. H., and Lauritzen, L. (2018). Fish oil as a potential activator of brown and beige fat thermogenesis. Adipocyte 7, 88-95. doi: 10.1080/21623945. 2018.1442980

Ma, S., Yu, H., Zhao, Z., Luo, Z., Chen, J., Ni, Y., et al. (2012). Activation of the coldsensing TRPM8 channel triggers UCP1-dependent thermogenesis and prevents obesity. J. Mol. Cell Biol. 4, 88-96. doi: 10.1093/jmcb/mjs001

Maharani, A., and Tampubolon, G. (2016). National Economic Development Status May Affect the Association between Central Adiposity and Cognition in Older Adults. PLoS One 11:e0148406. doi: 10.1371/journal.pone. 0148406

Mako, K., Yasushi, K., Katsuhiro, N., Michihiro, T., Yoshihiro, K., and Osamu, S. (2015). Auto-oxidation Products of Epigallocatechin Gallate Activate TRPA1 and TRPV1 in Sensory Neurons. Chem. Senses 2015, 27-46.

Martinez-Botas, J., Anderson, J. B., Tessier, D., Lapillonne, A., Chang, B. H., Quast, M. J., et al. (2000). Absence of perilipin results in leanness and reverses obesity in Lepr(db/db) mice. Nat. Genet. 26, 474-479. doi: 10.1038/82630

Masamoto, Y., Kawabata, F., and Fushiki, T. (2009). Intragastric administration of TRPV1, TRPV3, TRPM8, and TRPA1 agonists modulates autonomic thermoregulation in different manners in mice. Biosci. Biotechnol. Biochem. 73, 1021-1027. doi: 10.1271/bbb.80796

McKemy, D. D., Neuhausser, W. M., and Julius, D. (2002). Identification of a cold receptor reveals a general role for TRP channels in thermosensation. Nature 416, 52-58. doi: 10.1038/nature719

Monet, M., Gkika, D., Lehen'kyi, V., Pourtier, A., Vanden Abeele, F., Bidaux, G., et al. (2009). Lysophospholipids stimulate prostate cancer cell migration via TRPV2 channel activation. Biochim. Biophys. Acta 1793, 528-539. doi: 10.1016/ j.bbamcr.2009.01.003

Montell, C., and Rubin, G. M. (1989). Molecular characterization of the Drosophila trp locus: a putative integral membrane protein required for phototransduction. Neuron 2, 1313-1323.

Moraes, M. N., de Assis, L. V. M., Henriques, F. D. S., Batista, M. L. Jr., Guler, A. D., and Castrucci, A. M. L. (2017). Cold-sensing TRPM8 channel participates in circadian control of the brown adipose tissue. Biochim. Biophys. Acta Mol. Cell Res. 1864, 2415-2427. doi: 10.1016/j.bbamcr.2017.09.011

Moran, M. M., Xu, H., and Clapham, D. E. (2004). TRP ion channels in the nervous system. Curr. Opin. Neurobiol. 14, 362-369. doi: 10.1016/j.conb.2004.05. 003

Muraki, K., Iwata, Y., Katanosaka, Y., Ito, T., Ohya, S., Shigekawa, M., et al. (2003). TRPV2 is a component of osmotically sensitive cation channels in murine aortic myocytes. Circ. Res. 93, 829-838. doi: 10.1161/01.RES.0000097263.102 $20.0 \mathrm{C}$

Nagai, N., Sakane, N., Fujishita, A., Fujiwara, R., Kimura, T., Kotani, K., et al. (2007). The -3826 A -> G variant of the uncoupling protein-1 gene diminishes thermogenesis during acute cold exposure in healthy children. Obes. Res. Clin. Pract. 1, I-II. doi: 10.1016/j.orcp.2007.02.001

NCD Risk Factor Collaboration (2016). Trends in adult body-mass index in 200 countries from 1975 to 2014: a pooled analysis of 1698 population-based measurement studies with 19.2 million participants. Lancet 387, 1377-1396. doi: 10.1016/S0140-6736(16)30054-X

Nedergaard, J., and Cannon, B. (2010). The changed metabolic world with human brown adipose tissue: therapeutic visions. Cell Metab. 11, 268-272. doi: 10.1016/ j.cmet.2010.03.007

Nedergaard, J., Bengtsson, T., and Cannon, B. (2011). New powers of brown fat: fighting the metabolic syndrome. Cell Metab. 13, 238-240. doi: 10.1016/j.cmet. 2011.02.009

Nedergaard, J., Ricquier, D., and Kozak, L. P. (2005). Uncoupling proteins: current status and therapeutic prospects. EMBO Rep. 6, 917-921. doi: 10.1038/sj.embor. 7400532

Nguyen, D. M., and El-Serag, H. B. (2010). The epidemiology of obesity. Gastroenterol. Clin. North Am. 39, 1-7. doi: 10.1016/j.gtc.2009.12.014

Ohyama, K., Nogusa, Y., Shinoda, K., Suzuki, K., Bannai, M., Kajimura, S., et al. (2016). A Synergistic Antiobesity Effect by a Combination of Capsinoids and Cold Temperature Through Promoting Beige Adipocyte Biogenesis. Diabetes $65,1410-1423$.

Oi-Kano, Y., Iwasaki, Y., Nakamura, T., Watanabe, T., Goto, T., Kawada, T., et al. (2016). Oleuropein aglycone enhances UCP1 expression in brown adipose tissue in high-fat-diet-induced obese rats by activating $\beta$-adrenergic signaling. J. Nutrit. Biochem. 40, 209-218. 
Okumura, Y., Narukawa, M., Iwasaki, Y., Ishikawa, A., Matsuda, H., Yoshikawa, M., et al. (2010). Activation of TRPV1 and TRPA1 by Black Pepper Components. Biosci. Biotechnol. Biochem. 74, 1068-1072.

Orava, J., Nuutila, P., Lidell, M. E., Oikonen, V., Noponen, T., Viljanen, T., et al. (2011). Different metabolic responses of human brown adipose tissue to activation by cold and insulin. Cell Metab. 14, 272-279. doi: 10.1016/j.cmet. 2011.06.012

Ouellet, V., Routhier-Labadie, A., Bellemare, W., Lakhal-Chaieb, L., Turcotte, E., Carpentier, A. C., et al. (2011). Outdoor temperature, age, sex, body mass index, and diabetic status determine the prevalence, mass, and glucose-uptake activity of 18F-FDG-detected BAT in humans. J. Clin. Endocrinol. Metab. 96, 192-199. doi: 10.1210/jc.2010-0989

Park, A., Kim, W. K., and Bae, K. H. (2014). Distinction of white, beige and brown adipocytes derived from mesenchymal stem cells. World J. Stem Cells 2014:33.

Paulsen, C. E., Armache, J. P., Gao, Y., Cheng, Y., and Julius, D. (2015). Structure of the TRPA1 ion channel suggests regulatory mechanisms. Nature 520, 511-517. doi: 10.1038/nature14367

Pfannenberg, C., Werner, M. K., Ripkens, S., Stef, I., Deckert, A., Schmadl, M., et al. (2010). Impact of age on the relationships of brown adipose tissue with sex and adiposity in humans. Diabetes 59, 1789-1793. doi: 10.2337/db10-0004

Ramsey, I. S., Delling, M., and Clapham, D. E. (2006). An introduction to TRP channels. Annu. Rev. Physiol. 68, 619-647. doi: 10.1146/annurev.physiol.68. 040204.100431

Reilly, S. M., and Saltiel, A. R. (2017). Adapting to obesity with adipose tissue inflammation. Nat. Rev. Endocrinol. 13, 633-643. doi: 10.1038/nrendo.2017.90

Ricquier, D., and Kader, J. C. (1976). Mitochondrial protein alteration in active brown fat: A sodium dodecyl sulfate-polyacrylamide gel electrophoretic study. Biochem. Biophys. Res. Commun. 73, 577-583.

Rossato, M., Granzotto, M., Macchi, V., Porzionato, A., Petrelli, L., Calcagno, A., et al. (2014). Human white adipocytes express the cold receptor TRPM8 which activation induces UCP1 expression, mitochondrial activation and heat production. Mol. Cell Endocrinol. 383, 137-146. doi: 10.1016/j.mce.2013.12.005

Saito, M., and Yoneshiro, T. (2013). Capsinoids and related food ingredients activating brown fat thermogenesis and reducing body fat in humans. Curr. Opin. Lipidol. 24, 71-77. doi: 10.1097/MOL.0b013e32835a4f40

Saito, M., Matsushita, M., Yoneshiro, T., and Okamatsu-Ogura, Y. (2020). Brown Adipose Tissue, Diet-Induced Thermogenesis, and Thermogenic Food Ingredients: From Mice to Men. Front. Endocrinol. 11:222. doi: 10.3389/fendo. 2020.00222

Sakellariou, P., Valente, A., Carrillo, A. E., Metsios, G. S., Nadolnik, L., Jamurtas, A. Z., et al. (2016). Chronic l-menthol-induced browning of white adipose tissue hypothesis: A putative therapeutic regime for combating obesity and improving metabolic health. Med. Hypotheses 93, 21-26. doi: 10.1016/j.mehy.2016.05.006

Salazar, H., Llorente, I., Jara-Oseguera, A., García-Villegas, R., and Rosenbaum, T. (2008). A single N-terminal cysteine in TRPV1 determines activation by pungent compounds from onion and garlic. Nat. Neurosci. 11, 255-261.

Sanchez, J. C., Rivera, R. A., and Munoz, L. V. (2016). TRPV4 Channels in Human White Adipocytes: Electrophysiological Characterization and Regulation by Insulin. J. Cell Physiol. 231, 954-963. doi: 10.1002/jcp.25187

Sanders, O. D., Rajagopal, J. A., and Rajagopal, L. (2020). Menthol to Induce Nonshivering Thermogenesis via TRPM8/PKA Signaling for Treatment of Obesity. J. Obes. Metab. Syndr. 2020:jomes20038. doi: 10.7570/jomes20038

Sharp, L. Z., Shinoda, K., Ohno, H., Scheel, D. W., Tomoda, E., Ruiz, L., et al. (2012). Human BAT possesses molecular signatures that resemble beige/brite cells. PLoS One 7:e49452. doi: 10.1371/journal.pone.0049452

Shin, K. O., and Moritani, T. (2007). Alterations of autonomic nervous activity and energy metabolism by capsaicin ingestion during aerobic exercise in healthy men. J. Nutr. Sci. Vitaminol. 53, 124-132.

Shirkhani, S., Marandi, S. M., Kazeminasab, F., Esmaeili, M., Ghaedi, K., Esfarjani, F., et al. (2018). Comparative studies on the effects of high-fat diet, endurance training and obesity on Ucp1 expression in male C57BL/6 mice. Gene 676, 16-21. doi: 10.1016/j.gene.2018.07.015

Singh, R., Bansal, Y., Sodhi, R. K., Singh, D. P., and Kuhad, A. (2020). Berberine attenuated olanzapine-induced metabolic alterations in mice: Targeting transient receptor potential vanilloid type 1 and 3 channels. Life Sci. 247:117442.

Snitker, S., Fujishima, Y., Shen, H., Ott, S., Pi-Sunyer, X., Furuhata, Y., et al. (2009). Effects of novel capsinoid treatment on fatness and energy metabolism in humans: possible pharmacogenetic implications. Am. J. Clin. Nutr. 89, 45-50. doi: 10.3945/ajen.2008.26561 high-thermogenic brown adipocyte subpopulations coexist in murine adipose tissue. J. Clin. Invest. 130, 247-257. doi: 10.1172/JCI129167

Story, G. M., Peier, A. M., Reeve, A. J., Eid, S. R., Mosbacher, J., Hricik, T. R., et al. (2003). ANKTM1, a TRP-like channel expressed in nociceptive neurons, is activated by cold temperatures. Cell 112, 819-829. doi: 10.1016/s0092-8674(03) 00158-2

Strotmann, R., Harteneck, C., Nunnenmacher, K., Schultz, G., and Plant, T. D. (2000). OTRPC4, a nonselective cation channel that confers sensitivity to extracellular osmolarity. Nat. Cell Biol. 2, 695-702. doi: 10.1038/35036318

Sukumar, P., Sedo, A., Li, J., Wilson, L. A., O’Regan, D., Lippiat, J. D., et al. (2012). Constitutively active TRPC channels of adipocytes confer a mechanism for sensing dietary fatty acids and regulating adiponectin. Circ. Res. 111, 191-200. doi: 10.1161/CIRCRESAHA.112.270751

Sun, W., Li, C., Zhang, Y., Jiang, C., Zhai, M., Zhou, Q., et al. (2017a). Gene expression changes of thermo-sensitive transient receptor potential channels in obese mice. Cell Biol. Int. 41, 908-913. doi: 10.1002/cbin.10783

Sun, W., Uchida, K., and Tominaga, M. (2017b). TRPV2 regulates BAT thermogenesis and differentiation. Channels 11, 94-96. doi: 10.1080/19336950. 2016.1228401

Sun, W., Uchida, K., Suzuki, Y., Zhou, Y., Kim, M., Takayama, Y., et al. (2016a). Lack of TRPV2 impairs thermogenesis in mouse brown adipose tissue. EMBO Rep. 17, 383-399. doi: 10.15252/embr.201540819

Sun, W., Uchida, K., Takahashi, N., Iwata, Y., Wakabayashi, S., Goto, T., et al. (2016b). Activation of TRPV2 negatively regulates the differentiation of mouse brown adipocytes. Pflugers Arch. 468, 1527-1540. doi: 10.1007/s00424-0161846-1

Sun, W., Yu, Z., Yang, S., Jiang, C., Kou, Y., Xiao, L., et al. (2020). A Transcriptomic Analysis Reveals Novel Patterns of Gene Expression During 3T3-L1 Adipocyte Differentiation. Front. Mol. Biosci. 7:564339. doi: 10.3389/fmolb.2020.564339

Tabur, S., Oztuzcu, S., Duzen, I. V., Eraydin, A., Eroglu, S., Ozkaya, M., et al. (2015). Role of the transient receptor potential (TRP) channel gene expressions and TRP melastatin (TRPM) channel gene polymorphisms in obesity-related metabolic syndrome. Eur. Rev. Med. Pharmacol. Sci. 19, 1388-1397.

Tajino, K., Hosokawa, H., Maegawa, S., Matsumura, K., Dhaka, A., and Kobayashi, S. (2011). Cooling-sensitive TRPM8 is thermostat of skin temperature against cooling. PLoS One 6:e17504. doi: 10.1371/journal.pone.0017504

Tajino, K., Matsumura, K., Kosada, K., Shibakusa, T., Inoue, K., Fushiki, T., et al. (2007). Application of menthol to the skin of whole trunk in mice induces autonomic and behavioral heat-gain responses. Am. J. Physiol. Regul. Integr. Comp. Physiol. 293, R2128-R2135. doi: 10.1152/ajpregu.00377.2007

Talavera, K., Startek, J. B., Alvarez-Collazo, J., Boonen, B., Alpizar, Y. A., Sanchez, A., et al. (2020). Mammalian Transient Receptor Potential TRPAl Channels: From Structure to Disease. Physiol. Rev. 100, 725-803. doi: 10.1152/physrev. 00005.2019

Tamura, Y., Iwasaki, Y., Narukawa, M., and Watanabe, T. (2012). Ingestion of cinnamaldehyde, a TRPA1 agonist, reduces visceral fats in mice fed a high-fat and high-sucrose diet. J. Nutrit. Sci. Vitaminol. 58:9.

Thodeti, C. K., Matthews, B., Ravi, A., Mammoto, A., Ghosh, K., Bracha, A. L., et al. (2009). TRPV4 channels mediate cyclic strain-induced endothelial cell reorientation through integrin-to-integrin signaling. Circ. Res. 104, 1123-1130. doi: 10.1161/CIRCRESAHA.108.192930

Uchida, K., Dezaki, K., Yoneshiro, T., Watanabe, T., Yamazaki, J., Saito, M., et al. (2017). Involvement of thermosensitive TRP channels in energy metabolism. J. Physiol. Sci. 67, 549-560. doi: 10.1007/s12576-017-0552-x

Uchida, K., Sun, W., Yamazaki, J., and Tominaga, M. (2018). Role of ThermoSensitive Transient Receptor Potential Channels in Brown Adipose Tissue. Biol. Pharm. Bull. 41, 1135-1144. doi: 10.1248/bpb.b18-00063

Ussher, J. R., Koves, T. R., Cadete, V. J., Zhang, L., Jaswal, J. S., Swyrd, S. J., et al. (2010). Inhibition of de novo ceramide synthesis reverses diet-induced insulin resistance and enhances whole-body oxygen consumption. Diabetes 59, 2453-2464. doi: 10.2337/db09-1293

Valente, A., Carrillo, A. E., Tzatzarakis, M. N., Vakonaki, E., Tsatsakis, A. M., Kenny, G. P., et al. (2015). The absorption and metabolism of a single L-menthol oral versus skin administration: Effects on thermogenesis and metabolic rate. Food Chem. Toxicol. 86, 262-273. doi: 10.1016/j.fct.2015.09.018 
van Marken Lichtenbelt, W. D., Vanhommerig, J. W., Smulders, N. M., Drossaerts, J. M., Kemerink, G. J., Bouvy, N. D., et al. (2009). Cold-activated brown adipose tissue in healthy men. N. Engl. J. Med. 360, 1500-1508. doi: 10.1056/ NEJMoa0808718

Wahlqvist, M. L., and Wattanapenpaiboon, N. (2001). Hot foods-unexpected help with energy balance? Lancet 358, 348-349. doi: 10.1016/S0140-6736(01)0 5586-6

Watanabe, H., Davis, J. B., Smart, D., Jerman, J. C., Smith, G. D., Hayes, P., et al. (2002a). Activation of TRPV4 channels (hVRL-2/mTRP12) by phorbol derivatives. J. Biol. Chem. 277, 13569-13577. doi: 10.1074/jbc.M2000 62200

Watanabe, H., Vriens, J., Suh, S. H., Benham, C. D., Droogmans, G., and Nilius, B. (2002b). Heat-evoked activation of TRPV4 channels in a HEK293 cell expression system and in native mouse aorta endothelial cells. J. Biol. Chem. 277, 47044-47051. doi: 10.1074/jbc.M208277200

Watanabe, T., and Terada, Y. (2015). Food Compounds Activating Thermosensitive TRP Channels in Asian Herbal and Medicinal Foods. J. Nutr. Sci. Vitaminol. 61(Suppl.), S86-S88. doi: 10.3177/jnsv.61.S86

Willette, R. N., Bao, W., Nerurkar, S., Yue, T. L., Doe, C. P., Stankus, G., et al. (2008). Systemic activation of the transient receptor potential vanilloid subtype 4 channel causes endothelial failure and circulatory collapse: Part 2. J. Pharmacol. Exp. Ther. 326, 443-452. doi: 10.1124/jpet.107.134551

Wolfrum, C., Kiehlmann, E., and Pelczar, P. (2018). TRPC1 regulates brown adipose tissue activity in a PPARgamma-dependent manner. Am. J. Physiol. Endocrinol. Metab. 315, E825-E832. doi: 10.1152/ajpendo.00170.2017

Wu, J., Bostrom, P., Sparks, L. M., Ye, L., Choi, J. H., Giang, A. H., et al. (2012). Beige adipocytes are a distinct type of thermogenic fat cell in mouse and human. Cell 150, 366-376. doi: 10.1016/j.cell.2012.05.016

Wu, L. J., Sweet, T. B., and Clapham, D. E. (2010). International Union of Basic and Clinical Pharmacology. LXXVI. Current progress in the mammalian TRP ion channel family. Pharmacol. Rev. 62, 381-404. doi: 10.1124/pr.110.00 2725

Wu, M., Junker, D., Branca, R. T., and Karampinos, D. C. (2020). Magnetic Resonance Imaging Techniques for Brown Adipose Tissue Detection. Front. Endocrinol. 11:421. doi: 10.3389/fendo.2020.00421

Ye, L., Kleiner, S., Wu, J., Sah, R., Gupta, R. K., Banks, A. S., et al. (2012). TRPV4 is a regulator of adipose oxidative metabolism, inflammation, and energy homeostasis. Cell 151, 96-110. doi: 10.1016/j.cell.2012.08.034
Ye, L., Wu, J., Cohen, P., Kazak, L., Khandekar, M. J., Jedrychowski, M. P., et al. (2013). Fat cells directly sense temperature to activate thermogenesis. Proc. Natl. Acad. Sci. U S A. 110, 12480-12485. doi: 10.1073/pnas.1310261110

Yoneshiro, T., Aita, S., Kawai, Y., Iwanaga, T., and Saito, M. (2012). Nonpungent capsaicin analogs (capsinoids) increase energy expenditure through the activation of brown adipose tissue in humans. Am. J. Clin. Nutr. 95, 845-850. doi: 10.3945/ajcn.111.018606

Yoneshiro, T., Aita, S., Matsushita, M., Kameya, T., Nakada, K., Kawai, Y., et al. (2011). Brown adipose tissue, whole-body energy expenditure, and thermogenesis in healthy adult men. Obesity 19, 13-16. doi: 10.1038/oby.20 10.105

Yoneshiro, T., Ogawa, T., Okamoto, N., Matsushita, M., Aita, S., Kameya, T., et al. (2013). Impact of UCP1 and beta3AR gene polymorphisms on age-related changes in brown adipose tissue and adiposity in humans. Int. J. Obes. 37, 993-998. doi: 10.1038/ijo.2012.161

Zhai, M., Yang, D., Yi, W., and Sun, W. (2020). Involvement of calcium channels in the regulation of adipogenesis. Adipocyte 9, 132-141. doi: 10.1080/21623945. 2020.1738792

Zhang, L. L., Yan Liu, D., Ma, L. Q., Luo, Z. D., Cao, T. B., Zhong, J., et al. (2007). Activation of transient receptor potential vanilloid type-1 channel prevents adipogenesis and obesity. Circ. Res. 100, 1063-1070. doi: 10.1161/01. RES.0000262653.84850.8b

Zsombok, A., and Derbenev, A. (2016). TRP Channels as Therapeutic Targets in Diabetes and Obesity. Pharmaceuticals 9:50.

Zubcevic, L., Herzik, M. A. Jr., Chung, B. C., Liu, Z., Lander, G. C., and Lee, S. Y. (2016). Cryo-electron microscopy structure of the TRPV2 ion channel. Nat. Struct. Mol. Biol. 23, 180-186. doi: 10.1038/nsmb.3159

Conflict of Interest: The authors declare that the research was conducted in the absence of any commercial or financial relationships that could be construed as a potential conflict of interest.

Copyright (c) 2021 Sun, Luo, Zhang, Tang and Zhu. This is an open-access article distributed under the terms of the Creative Commons Attribution License (CC BY). The use, distribution or reproduction in other forums is permitted, provided the original author(s) and the copyright owner(s) are credited and that the original publication in this journal is cited, in accordance with accepted academic practice. No use, distribution or reproduction is permitted which does not comply with these terms. 